\title{
SYNTHESIS OF ISOCHROMANES AND ISOTHIOCHROMANES \\ BEARING FLUORINATED ONE-CARBON UNITS VIA \\ INTRAMOLECULAR CYCLIZATIONS OF ORTHO-SUBSTITUTED $\alpha$-(TRIFLUOROMETHYL)STYRENES
}

\section{Junji Ichikawa,* Masahiro Ikeda, Masahiro Hattori}

Department of Chemistry, Graduate School of Pure and Applied Sciences, University of Tsukuba, Tsukuba, Ibaraki 305-8571

junji@chem.tsukuba.ac.jp

This paper is dedicated to Professor Keiichiro Fukumoto in celebration of his 75th birthday.

\begin{abstract}
Trifluoromethyl)styrenes bearing a nucleophilic oxygen or sulfur atom tethered by a methylene or methyne unit at the ortho carbon were prepared by the coupling reaction of 2-bromo-3,3,3trifluoropropene with aryl iodides via (3,3,3-trifluoroprop-1-en-2yl)boronic acid. The styrenes thus obtained readily undergo an intramolecular nucleophilic addition or substitution $\left(\mathrm{S}_{\mathrm{N}} 2^{\prime}\right.$-type $)$ of the oxygen and sulfur under basic conditions, leading to 4-trifluoromethylor 4-difluoromethylene-substituted isochromanes and isothiochromanes, respectively.
\end{abstract}

\section{INTRODUCTION}

Isochromane (3,4-dihydro-1H-2-benzopyran $)^{1}$ and isothiochromane (3,4-dihydro- $1 H$-2-benzothiopyran $)^{2}$ derivatives constitute an important class of natural and synthetic compounds. Because they exhibit a wide variety of biological activities, iso(thio)chromane skeletons are frequently found in the structures of drugs 
and drug candidates. Moreover, they are structural analogues of tetrahydroisoquinolines, which are widespread in the alkaloid family. ${ }^{3}$ Hence, there have been many reports on the use of iso(thio)chromanes as starting materials or intermediates for the synthesis of medicinal and agrochemical agents. ${ }^{4}$

While the synthesis of iso(thio)chromanes has been extensively studied, ${ }^{1,2,5}$ a quite limited number of reports have appeared on the synthesis of their partially fluorinated counterparts. ${ }^{6}$ The introduction of fluorocarbon substituents into heterocycles has come into wide use as one of the most efficient methods for modification of biological activity, as well as of physical and chemical properties. ${ }^{7,8}$ In particular, the incorporation of a trifluoromethyl $\left(\mathrm{CF}_{3}\right)$ group into organic molecules increases lipophilicity and affects electron density. ${ }^{9}$ An exo-difluoromethylene $\left(=\mathrm{CF}_{2}\right)$ group acts as a reactive site toward nucleophiles, ${ }^{10,11}$ and its reduction provides a difluoromethyl $\left(\mathrm{CHF}_{2}\right)$ group, ${ }^{12}$ which raises lipophilicity and functions as a hydrogen-bond donor without nucleophilicity. ${ }^{13}$ Thus, the development of a synthetic method for iso(thio)chromanes with these fluorinated one-carbon units is a highly desirable goal.

$\alpha$-(Trifluoromethyl)styrenes are susceptible to nucleophilic attack, because of the electron-withdrawing trifluoromethyl group. Utilizing this reactivity, we have recently found that the (trifluoromethyl)styrenes with a nitrogen functionality readily undergo an intramolecular addition or $S_{\mathrm{N}} 2^{\prime}$-type reaction, depending on conditions with or without a proton source. These reactions provided quinoline and isoquinoline derivatives bearing a fluorinated one-carbon unit such as a $\mathrm{CF}_{3}, \mathrm{CHF}_{2}$, or $=\mathrm{CF}_{2}$ group. ${ }^{14}$

In a continuation of our research on the cyclizations of 2-trifluoromethyl-1-alkenes, ${ }^{14,15}$ we sought to apply the intramolecular addition and substitution concept to the construction of 6-membered oxygen- or sulfur-containing heterocycles, isochromane and isothiochromane derivatives. On the basis of these considerations, $\alpha$-(trifluoromethyl)styrene derivatives were designed to bear a nucleophilic oxygen or a sulfur atom tethered by a methylene or methyne unit at the ortho carbon. They were subjected to the ringforming reactions in a 6-endo-trig fashion under basic conditions. Herein we wish to report the results of our studies on the synthesis of 4-trifluoromethyl- or 4-difluoromethylene-substituted isochromanes and isothiochromanes.

\section{RESULTS AND DISCUSSION}

\section{Preparation of $\alpha$-(Trifluoromethyl)styrenes Bearing a Nucleophilic Oxygen or Sulfur Atom}

The cyclization precursors, $o$-substituted $\alpha$-(trifluoromethyl)styrenes, were easily prepared by the Suzuki-Miyaura cross-coupling reaction of aryl iodides with (3,3,3-trifluoroprop-1-en-2-yl)boronic acid 
(2) that was prepared from 2-bromo-3,3,3-trifluoropropene (1), according to a modified literature procedure (Scheme 1). ${ }^{14 a, 16}$ (Trifluoromethyl)styrene 3a bearing a hydroxymethyl group at the ortho position, precursors of isochromanes, was successfully obtained in $88 \%$ yield via the coupling of 2 with $o$-iodobenzyl alcohol (Scheme 1, route A). Alcohols 3 were also obtained via another route, which allows the introduction of a substituent (R) on the benzylic carbon (route B). The coupling of 2 with $o$ iodobenzaldehyde afforded (trifluoromethyl)styrene $\mathbf{4}$ bearing an $o$-formyl group in $81 \%$ yield. The addition of nucleophiles such as Grignard reagents to $\mathbf{4}$ selectively occurred at the formyl carbon to provide $\mathbf{3 b}$ and $\mathbf{3 c}$.

As sulfur-containing substrates for the synthesis of isothiochromanes, thioacetates 6 were readily prepared from alcohols $\mathbf{3}$ via the corresponding mesylates $\mathbf{5}$ by the introduction of an acetylthio (AcS) group at the benzylic position on treatment with the 1,8-diazabicyclo[5.4.0]undec-7-ene (DBU) salt of ethanethioic $S$-acid (Scheme 1, route C).

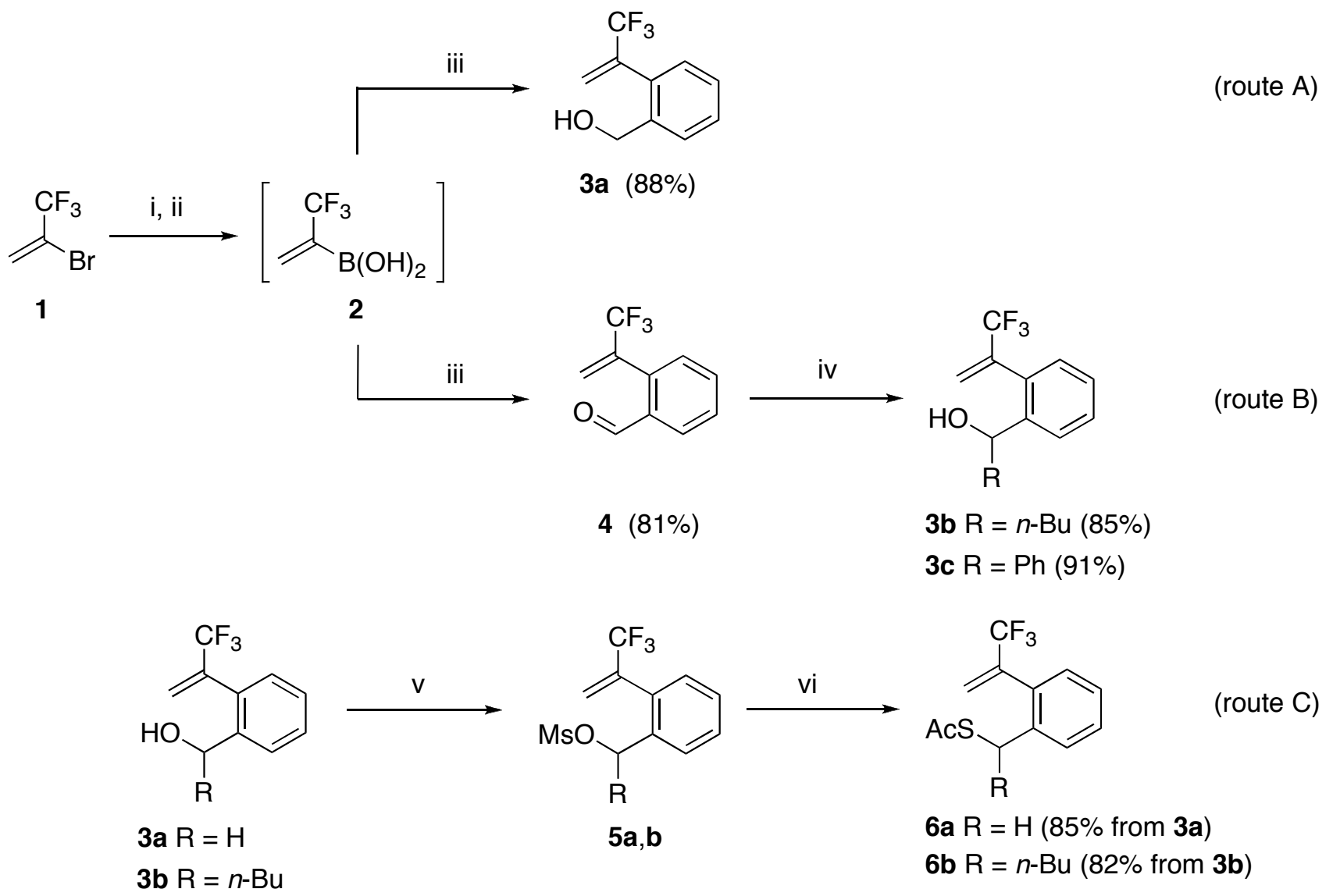

i, $\mathrm{Mg}$ (1.2 equiv), $\mathrm{B}(\mathrm{OMe})_{3}$ (3.0 equiv), THF, $0{ }^{\circ} \mathrm{C}, 3 \mathrm{~h}$; ii, $6 \mathrm{M} \mathrm{HCl} \mathrm{aq,} \mathrm{THF,} \mathrm{rt;} \mathrm{iii,} \mathrm{Arl} \mathrm{(3a:} 0.6$ equiv; 4: 0.3 equiv), $\mathrm{Pd}\left(\mathrm{PPh}_{3}\right)_{4}$ (3a: 0.01 equiv; 4 : 0.005 equiv), $1 \mathrm{M} \mathrm{Na}_{2} \mathrm{CO}_{3}$ aq (3a: 0.6 equiv; $4: 0.3$ equiv), toluene$\mathrm{MeOH}(5: 1), 70^{\circ} \mathrm{C}, 3 \mathbf{3 a :} 16 \mathrm{~h} ; \mathbf{4 : 3 2} \mathrm{h}$; iv, 3b: $n-\mathrm{BuMgBr}\left(1.2\right.$ equiv), $\mathrm{Et}_{2} \mathrm{O},-78^{\circ} \mathrm{C}, 0.5 \mathrm{~h}$ then rt, $3 \mathrm{~h} ; \mathbf{3 c}$ : $\mathrm{PhMgBr}\left(1.2\right.$ equiv), $\mathrm{Et}_{2} \mathrm{O},-78^{\circ} \mathrm{C}, 0.5 \mathrm{~h}$ then rt, $3 \mathrm{~h} ; \mathrm{v}, \mathrm{MsCl}$ (1.2 equiv), $\mathrm{Et}_{3} \mathrm{~N}$ (1.5 equiv), $\mathrm{CH}_{2} \mathrm{Cl}_{2}, 0{ }^{\circ} \mathrm{C}$, $2 \mathrm{~h}$; vi, AcSH (3.0 equiv), DBU (3.0 equiv), DMF, rt, $20 \mathrm{~h}$. 


\section{Scheme 1. Preparation of $\alpha$-(trifluoromethyl)styrenes functionalized at the ortho position.}

\section{Cyclization of $\alpha$-(Trifluoromethyl)styrenes Bearing a Nucleophilic Oxygen or Sulfur Atom}

We first examined the cyclization of (trifluoromethyl)styrenes $\mathbf{3}$ with a nucleophilic oxygen as precursors of isochromanes. Intramolecular addition of $\mathbf{3 a}$ was attempted under basic conditions with a proton source to trap the intermediary trifluoromethylated carbanion. Treatment of $\mathbf{3 a}$ with $\mathrm{KOH}$ (1.5 equiv) in ethylene glycol (ethane-1,2-diol) gave the desired cyclic product 7a in 37\% yield, whereas the addition was more successfully effected by the use of DBU (1.1 equiv) in diglyme [bis(2-methoxyethyl) ether] at $120{ }^{\circ} \mathrm{C}$ (Table 1, Entry 1), where the hydroxy group of $\mathbf{3 a}$ and/or $\mathrm{DBU} \cdot \mathrm{H}^{+}$acted as a proton donor. 4Trifluoromethylated isochromane $7 \mathbf{a}$ was obtained in $82 \%$ yield without formation of a substitution product 8a (vide infra). In the case of secondary alcohols $\mathbf{3 b}, \mathbf{c}$, ring closure also occurred under similar conditions, leading to 1,4-disubstituted isochromanes $\mathbf{7 b , c}$ in 72 and $86 \%$ yields with 87:13 and 57:43 diastereomer ratios, respectively (Entries 2 and 3).

Chromane precursors $\mathbf{3}$ were next subjected to basic conditions in the absence of a proton source to attempt intramolecular substitution, leading to 4-difluoromethylenated isochromanes 8 . Treatment with $\mathrm{NaH}$ in dimethylformamide (DMF) mainly caused decomposition of 3a and afforded the expected $\mathrm{S}_{\mathrm{N}} 2^{\prime}-$ type product $8 \mathbf{a}$ only in $10 \%$ yield along with $7 \mathbf{a}$ in $20 \%$ yield. After screening of basic conditions, we found that treatment with $\mathrm{K}_{3} \mathrm{PO}_{4}(2.0$ equiv) in $\mathrm{DMF}$ improved the yield of $8 \mathbf{a}$ to $38 \%$ with the accompanying formation of $\mathbf{7 a}$ in $11 \%$ yield (Entry 4$)$.

Table 1. Synthesis of 4-trifluoromethylated and 4-difluoromethylenated isochromanes. 


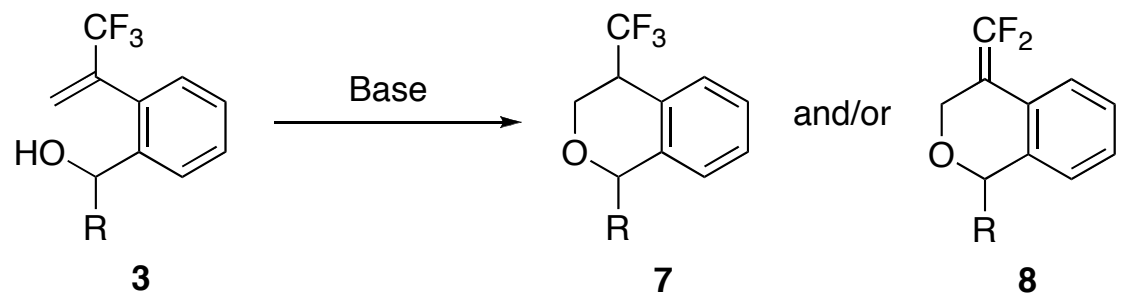

\begin{tabular}{ccccccc}
\hline \multirow{2}{*}{ Entry } & $\mathrm{R} \mathrm{(3)}$ & Base (equiv) & Solvent & Conditions & \multicolumn{2}{c}{ Yield (\%) $^{\mathrm{a}}$} \\
\hline 1 & $\mathrm{H}(\mathbf{3 a})$ & $\mathrm{DBU}(1.1)$ & Diglyme & $120^{\circ} \mathrm{C}, 48 \mathrm{~h}$ & 82 & 0 \\
2 & $n-\mathrm{Bu}(\mathbf{3 b})$ & $\mathrm{DBU}(1.5)$ & Diglyme & $120^{\circ} \mathrm{C}, 96 \mathrm{~h}$ & $72(87: 13)^{\mathrm{b}}$ & 0 \\
3 & $\mathrm{Ph}(3 \mathbf{c})$ & $\mathrm{DBU}(1.1)$ & Diglyme & $120^{\circ} \mathrm{C}, 24 \mathrm{~h}$ & $86(57: 43)^{\mathrm{b}}$ & 0 \\
4 & $\mathrm{H} \mathrm{(3a)}$ & $\mathrm{K}_{3} \mathrm{PO}_{4}(2.0)$ & $\mathrm{DMF}$ & $120^{\circ} \mathrm{C}, 3 \mathrm{~h}$ & 11 & 38 \\
5 & $\mathrm{Ph}(3 \mathbf{c})$ & $\mathrm{K}_{3} \mathrm{PO}_{4}(2.0)$ & $\mathrm{DMF}$ & $120^{\circ} \mathrm{C}, 6 \mathrm{~h}$ & $8(69: 31)^{\mathrm{b}}$ & 43 \\
\hline
\end{tabular}

${ }^{\mathrm{a}}$ Isolated yield. ${ }^{\mathrm{b}}$ Diastereomer ratio determined by ${ }^{19} \mathrm{~F}$ NMR measurement.

We then tried the cyclizations via addition or substitution using sulfur nucleophiles, which would provide isothiochromanes. When thioacetates 6a,b were treated with $\mathrm{K}_{2} \mathrm{CO}_{3}$ (1.1 equiv) in $\mathrm{MeOH}$, the deacetylation of $\mathbf{6}$ occurred to generate the corresponding thiolates, whose intramolecular addition readily proceeded in the presence of a proton source. The desired products, 4-trifluoromethylated isothiochromanes 9a,b were obtained in 92\% yield and 80\% yield with 57:43 diastereomer ratio, respectively (Table 2, Entries 1 and 2). In contrast, treatment of $\mathbf{6 a}, \mathbf{b}$ with sodium methoxide (2.0-3.0 equiv) in tetrahydrofuran (THF) promoted deacetylation followed by $S_{\mathrm{N}} 2$-type reaction instead of addition, which is due to the aprotic conditions. The two successive processes provided 4difluoromethylenated isothiochromanes 10a,b in $76 \%$ and $73 \%$ yields, respectively (Entries 3 and 4 ).

Table 2. Synthesis of 4-trifluoromethylated and 4-difluoromethylenated isothiochromanes. 


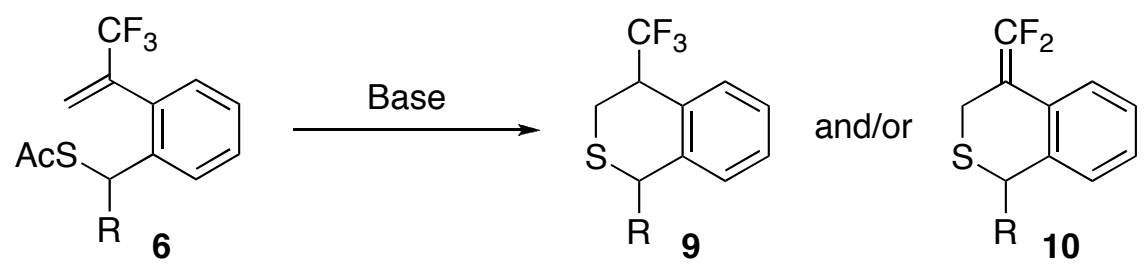

\begin{tabular}{|c|c|c|c|c|c|c|}
\hline \multirow{2}{*}{ Entry } & \multirow{2}{*}{$R(6)$} & \multirow{2}{*}{ Base (equiv) } & \multirow{2}{*}{ Solvent } & \multirow{2}{*}{ Conditions } & \multicolumn{2}{|c|}{ Yield (\%) } \\
\hline & & & & & 9 & 10 \\
\hline 1 & $\mathrm{H}(\mathbf{6 a})$ & $\mathrm{K}_{2} \mathrm{CO}_{3}(1.1)$ & $\mathrm{MeOH}$ & $0^{\circ} \mathrm{C}, 4 \mathrm{~h}$ & 92 & 4 \\
\hline 2 & $n-\mathrm{Bu}(6 \mathbf{b})$ & $\mathrm{K}_{2} \mathrm{CO}_{3}(1.1)$ & $\mathrm{MeOH}$ & reflux, $2 \mathrm{~h}$ & $80(57: 43)^{\mathrm{b}}$ & 3 \\
\hline 3 & $H(6 a)$ & $\mathrm{NaOMe}(2.0)$ & THF & $0{ }^{\circ} \mathrm{C}, 0.5 \mathrm{~h}$, then $\mathrm{rt}, 3 \mathrm{~h}$ & 10 & 76 \\
\hline 4 & $n$-Bu (6b) & NaOMe (3.0) & THF & reflux, $19 \mathrm{~h}$ & 0 & 73 \\
\hline
\end{tabular}

${ }^{\mathrm{a}}$ Isolated yield. ${ }^{\mathrm{b}}$ Diastereomer ratio determined by ${ }^{19} \mathrm{~F}$ NMR measurement.

In conclusion, the above results show that our intramolecular addition and substitution concept in 2trifluoromethyl-1-alkenes can be successfully applied to the construction of 6-membered oxygen- or sulfur-containig heterocycles as well as nitrogen-containing heterocycles. $o$-Substituted $\alpha$ (trifluoromethyl)styrenes, prepared from 2-bromo-3,3,3-trifluoro-1-propene and aryl iodides, readily undergo 6-endo ring closure via addition or substitution, depending on the reaction conditions. These reactions provide a facile method for the construction of selectively trifluoromethylated and difluoromethylenated benzo(thio)pyran frameworks.

\section{EXPERIMENTAL}

IR spectra were recorded by ATR (attenuated total reflectance) method. NMR spectra were recorded in $\mathrm{CDCl}_{3}$ at $500 \mathrm{MHz}\left({ }^{1} \mathrm{H} \mathrm{NMR}\right), 126 \mathrm{MHz}\left({ }^{13} \mathrm{C} \mathrm{NMR}\right)$, and $470 \mathrm{MHz}\left({ }^{19} \mathrm{~F}\right.$ NMR). Chemical shift values were given in ppm relative to internal $\mathrm{Me}_{4} \mathrm{Si}$ (for ${ }^{1} \mathrm{H} \mathrm{NMR}$ : $\delta 0.00$ ), $\mathrm{CDCl}_{3}$ (for ${ }^{13} \mathrm{C} \mathrm{NMR:} \delta 77.0$ ), and $\mathrm{C}_{6} \mathrm{~F}_{6}$ (for ${ }^{19} \mathrm{~F}$ NMR: $\delta_{\mathrm{F}} 0.0$ ). Column chromatography and preparative thin-layer chromatography (PTLC) were performed on silica gel. Unless otherwise noted, all reactions were conducted under nitrogen. Toluene, DMF, $\mathrm{CH}_{2} \mathrm{Cl}_{2}$, THF, and diethyl ether $\left(\mathrm{Et}_{2} \mathrm{O}\right)$ were dried by passing over a column of activated alumina (A-2, Purity) followed by a column of Q-5 scavenger (Engelhard). MeOH was distilled from Mg, and stored over molecular sieves $3 \AA$. Ethylene glycol and diglyme were distilled from $\mathrm{MgSO}_{4}$ and $\mathrm{CaH}_{2}$, respectively, and then stored over molecular sieves $4 \AA$. 
[2-(3,3,3-Trifluoroprop-1-en-2-yl)phenyl]methanol (3a): To a magnesium turnings (571 m g, 23.4 mmol) and trimethylborate $(6.51 \mathrm{~mL}, 58.5 \mathrm{mmol})$ in THF (40 mL) was added 2-bromo-3,3,3trifluoropropene $(2.00 \mathrm{~mL}, 19.5 \mathrm{mmol})$ in $\mathrm{THF}(5 \mathrm{~mL})$ over $1 \mathrm{~h}$ at $0{ }^{\circ} \mathrm{C}$. The reaction mixture was stirred at $0{ }^{\circ} \mathrm{C}$ for $3 \mathrm{~h}$. The reaction mixture was quenched with $\mathrm{HCl}(20 \mathrm{~mL}$ of $6 \mathrm{M}$ aqueous solution), and organic materials were extracted three times each with $\mathrm{Et}_{2} \mathrm{O}$. The combined extracts were washed with brine and then dried over $\mathrm{MgSO}_{4}$. Removal of the solvent under reduced pressure gave the residue, crude 1-(trifluoromethyl)vinylboronic acid (2) $\left[{ }^{19} \mathrm{~F} \mathrm{NMR}\left(\mathrm{CDCl}_{3}\right) \delta_{\mathrm{F}} 98.3(\mathrm{~s})\right]$, which was immediately used without purification in the following palladium-catalyzed coupling reaction with iodoarenes. The mixture of the crude boronic acid 2, 2-iodophenylmethanol (2.62 g, $11.2 \mathrm{mmol})$, sodium carbonate (12 mL of 1.0 $\mathrm{M}$ aqueous solution), $\mathrm{Pd}\left(\mathrm{PPh}_{3}\right)_{4}(259 \mathrm{mg}, 0.224 \mathrm{mmol})$ in toluene-MeOH (140 mL, 5:1) was stirred at $70{ }^{\circ} \mathrm{C}$ for $16 \mathrm{~h}$. The reaction was quenched with phosphate buffer $(\mathrm{pH} 7)$. The mixture was extracted with ethyl acetate three times. The combined extracts were washed with brine and dried over $\mathrm{Na}_{2} \mathrm{SO}_{4}$. After removal of the solvent under reduced pressure, the residue was purified by column chromatography (hexane-AcOEt 3:1) to give 3a (2.00 g, 88\%) as a colorless oil. ${ }^{1} \mathrm{H}$ NMR (500 MHz, $\left.\mathrm{CDCl}_{3}, \delta\right): 4.67$ (s, $2 \mathrm{H}), 5.60\left(\mathrm{q}, J_{\mathrm{HF}}=1.2 \mathrm{~Hz}, 1 \mathrm{H}\right), 6.15\left(\mathrm{q}, J_{\mathrm{HF}}=1.4 \mathrm{~Hz}, 1 \mathrm{H}\right), 7.26(\mathrm{~d}, J=7.6 \mathrm{~Hz}, 1 \mathrm{H}), 7.32(\mathrm{dd}, J=7.6,7.6$ $\mathrm{Hz}, 1 \mathrm{H}), 7.43(\mathrm{dd}, J=7.6,7.6 \mathrm{~Hz}, 1 \mathrm{H}), 7.57$ (d, $J=7.6 \mathrm{~Hz}, 1 \mathrm{H}) .{ }^{13} \mathrm{C} \mathrm{NMR}\left(126 \mathrm{MHz}, \mathrm{CDCl}_{3}, \delta\right): 62.7$, $122.8\left(\mathrm{q}, J_{\mathrm{CF}}=274 \mathrm{~Hz}\right), 123.5\left(\mathrm{q}, J_{\mathrm{CF}}=5 \mathrm{~Hz}\right), 127.5,128.4,129.3,129.8,132.4,136.9\left(\mathrm{q}, J_{\mathrm{CF}}=31 \mathrm{~Hz}\right)$, 139.4. ${ }^{19} \mathrm{~F}$ NMR (470 MHz, $\mathrm{CDCl}_{3}, \delta_{\mathrm{F}}$ ): 94.7 (s). IR (neat): 3330, 1342, 1217, 1169, 1115, 1072, $769 \mathrm{~cm}^{-1}$. Anal. Calcd for $\mathrm{C}_{10} \mathrm{H}_{9} \mathrm{OF}_{3}$ : C, 59.41; H, 4.49. Found: C, 59.21; H, 4.58.

2-(3,3,3-Trifluoroprop-1-en-2-yl)benzaldehyde (4): Compound 4 was prepared by the method described for 3a. Purification by column chromatography (hexane-AcOEt 5:1) gave 4 (81\%) as a colorless liquid. ${ }^{1} \mathrm{H}$ NMR (500 MHz, $\left.\mathrm{CDCl}_{3}, \delta\right): 5.62\left(\mathrm{q}, J_{\mathrm{HF}}=1.3 \mathrm{~Hz}, 1 \mathrm{H}\right), 6.29\left(\mathrm{q}, J_{\mathrm{HF}}=1.3 \mathrm{~Hz}, 1 \mathrm{H}\right)$, $7.41(\mathrm{~d}, J=7.6 \mathrm{~Hz}, 1 \mathrm{H}), 7.56(\mathrm{dd}, J=7.6,7.6 \mathrm{~Hz}, 1 \mathrm{H}), 7.63(\mathrm{dd}, J=7.6,7.6 \mathrm{~Hz}, 1 \mathrm{H}), 8.01(\mathrm{~d}, J=7.6 \mathrm{~Hz}$, $1 \mathrm{H}), 10.1(\mathrm{~s}, 1 \mathrm{H}) .{ }^{13} \mathrm{C} \mathrm{NMR}\left(126 \mathrm{MHz}, \mathrm{CDCl}_{3}, \delta\right): 122.4\left(\mathrm{q}, J_{\mathrm{CF}}=274 \mathrm{~Hz}\right), 125.1\left(\mathrm{q}, J_{\mathrm{CF}}=5 \mathrm{~Hz}\right), 128.4$, $129.5,130.7,133.6,134.8,135.4\left(\mathrm{q}, J_{\mathrm{CF}}=32 \mathrm{~Hz}\right), 136.6,190.8 .{ }^{19} \mathrm{~F}$ NMR (470 MHz, $\left.\mathrm{CDCl}_{3}, \delta_{\mathrm{F}}\right): 94.8(\mathrm{~s})$. IR (neat): 2858, 1701, 1599, 1346, 1173, 1126, $962 \mathrm{~cm}^{-1}$. Anal. Calcd for $\mathrm{C}_{10} \mathrm{H}_{7} \mathrm{OF}_{3}: \mathrm{C}, 60.01 ; \mathrm{H}, 3.53$. Found: C, 60.03; H, 3.66.

1-[2-(3,3,3-Trifluoroprop-1-en-2-yl)phenyl]pentan-1-ol (3b): To a solution of 4 (1.02 g, $5.09 \mathrm{mmol})$ in $\mathrm{Et}_{2} \mathrm{O}(45 \mathrm{ml})$ was added butylmagnesium bromide $\left(3.06 \mathrm{ml}, 2.0 \mathrm{M}\right.$ in $\left.\mathrm{Et}_{2} \mathrm{O}, 6.12 \mathrm{mmol}\right)$ at $-78{ }^{\circ} \mathrm{C}$. The 
reaction mixture was stirred at $-78{ }^{\circ} \mathrm{C}$ for $30 \mathrm{~min}$ and at room temperature for an additional $3 \mathrm{~h}$. Then, phosphate buffer ( $\mathrm{pH}$ 7) was added to quench the reaction. Organic materials were extracted with $\mathrm{Et}_{2} \mathrm{O}$ three times. The combined extracts were washed with brine and dried over $\mathrm{Na}_{2} \mathrm{SO}_{4}$. After removal of the solvent under reduced pressure, the residue was purified by column chromatography (hexane-AcOEt 3:1) to give $3 \mathbf{b}(1.12 \mathrm{~g}, 85 \%)$ as a colorless liquid. ${ }^{1} \mathrm{H}$ NMR $\left(500 \mathrm{MHz}, \mathrm{CDCl}_{3}, \delta\right): 0.88(\mathrm{t}, J=7.2 \mathrm{~Hz}, 3 \mathrm{H})$, $1.21-1.45(\mathrm{~m}, 4 \mathrm{H}), 1.62-1.69(\mathrm{~m}, 1 \mathrm{H}), 1.76-1.83(\mathrm{~m}, 2 \mathrm{H}), 4.79(\mathrm{dd}, J=8.3,5.0 \mathrm{~Hz}, 1 \mathrm{H}), 5.52\left(\mathrm{q}, J_{\mathrm{HF}}=\right.$ $1.2 \mathrm{~Hz}, 1 \mathrm{H}), 6.14\left(\mathrm{q}, J_{\mathrm{HF}}=1.4 \mathrm{~Hz}, 1 \mathrm{H}\right), 7.19(\mathrm{~d}, J=7.6 \mathrm{~Hz}, 1 \mathrm{H}), 7.28(\mathrm{dd}, J=7.6,7.6 \mathrm{~Hz}, 1 \mathrm{H}), 7.43(\mathrm{dd}$, $J=7.6,7.6 \mathrm{~Hz}, 1 \mathrm{H}), 7.60(\mathrm{~d}, J=7.6 \mathrm{~Hz}, 1 \mathrm{H}) .{ }^{13} \mathrm{C} \mathrm{NMR}\left(126 \mathrm{MHz}, \mathrm{CDCl}_{3}, \delta\right): 13.9,22.5,28.2,38.3,70.6$, $122.8\left(\mathrm{q}, J_{\mathrm{CF}}=274 \mathrm{~Hz}\right), 123.5\left(\mathrm{q}, J_{\mathrm{CF}}=5 \mathrm{~Hz}\right), 126.2,127.2,129.5,129.8,131.8,137.5\left(\mathrm{q}, J_{\mathrm{CF}}=31 \mathrm{~Hz}\right)$, 143.8. ${ }^{19} \mathrm{~F} \mathrm{NMR}\left(470 \mathrm{MHz}, \mathrm{CDCl}_{3}, \delta_{\mathrm{F}}\right): 94.5$ (s). IR (neat): 2933, 2862, 1340, 1167, 1124, 1095, 953, 762, $631 \mathrm{~cm}^{-1}$. Anal. Calcd for $\mathrm{C}_{14} \mathrm{H}_{17} \mathrm{OF}_{3}$ : C, 65.10; H, 6.63. Found: C, 65.45; H, 7.00.

Phenyl[2-(3,3,3-trifluoroprop-1-en-2-yl)phenyl]methanol (3c): Compound 3c was prepared by the method described for 3b. Purification by column chromatography (hexane-AcOEt 5:1) gave 4 (91\%) as a white solid. ${ }^{1} \mathrm{H}$ NMR $\left(500 \mathrm{MHz}, \mathrm{CDCl}_{3}, \delta\right): 2.12(\mathrm{~d}, J=3.8 \mathrm{~Hz}, 1 \mathrm{H}), 5.42\left(\mathrm{q}, J_{\mathrm{HF}}=1.1 \mathrm{~Hz}, 1 \mathrm{H}\right), 5.98(\mathrm{~d}$, $J=3.8 \mathrm{~Hz}, 1 \mathrm{H}), 6.12\left(\mathrm{q}, J_{\mathrm{HF}}=1.4 \mathrm{~Hz}, 1 \mathrm{H}\right), 7.24-7.28(\mathrm{~m}, 2 \mathrm{H}), 7.29-7.35(\mathrm{~m}, 5 \mathrm{H}), 7.40(\mathrm{dd}, J=7.6,7.6$ $\mathrm{Hz}, 1 \mathrm{H}), 7.51(\mathrm{~d}, J=7.6 \mathrm{~Hz}, 1 \mathrm{H}) .{ }^{13} \mathrm{C} \mathrm{NMR}\left(126 \mathrm{MHz} \mathrm{CDCl}_{3}, \delta\right): 72.5,122.9\left(\mathrm{q}, J_{\mathrm{CF}}=274 \mathrm{~Hz}\right), 124.2(\mathrm{q}$, $\left.J_{\mathrm{CF}}=5 \mathrm{~Hz}\right), 126.6,127.5,127.5,127.9,128.4,129.4,129.9,132.5,136.9\left(\mathrm{q}, J_{\mathrm{CF}}=31 \mathrm{~Hz}\right), 142.5,143.4$. ${ }^{19} \mathrm{~F}$ NMR (470 MHz, $\mathrm{CDCl}_{3}, \delta_{\mathrm{F}}$ ): 94.7 (s). IR (neat): 3334, 2921, 1342, 1403, 1169, 1122, 1016, $700 \mathrm{~cm}^{-1}$. Anal. Calcd for $\mathrm{C}_{16} \mathrm{H}_{13} \mathrm{OF}_{3}$ : C, 69.06; H, 4.71. Found: C, 68.92; H, 4.78.

$S$-[2-(3,3,3-Trifluoroprop-1-en-2-yl)phenyl]methyl ethanethioate (6a): Compound 6a was prepared by the method described for $\mathbf{6 b}$ (vide infra). Purification by PTLC (hexane-AcOEt 5:1) gave 6a (85\%) as a colorless liquid. ${ }^{1} \mathrm{H}$ NMR $\left(500 \mathrm{MHz}, \mathrm{CDCl}_{3}, \delta\right): 2.34(\mathrm{~s}, 3 \mathrm{H}), 4.13(\mathrm{~s}, 2 \mathrm{H}), 5.59\left(\mathrm{q}, J_{\mathrm{HF}}=1.3 \mathrm{~Hz}, 1 \mathrm{H}\right)$, $6.17\left(\mathrm{q}, J_{\mathrm{HF}}=1.4 \mathrm{~Hz}, 1 \mathrm{H}\right), 7.22(\mathrm{~d}, J=7.6 \mathrm{~Hz}, 1 \mathrm{H}), 7.27(\mathrm{dd}, J=7.6,7.6 \mathrm{~Hz}, 1 \mathrm{H}), 7.34(\mathrm{dd}, J=7.6,7.6$ $\mathrm{Hz}, 1 \mathrm{H}), 7.43(\mathrm{~d}, J=7.6 \mathrm{~Hz}, 1 \mathrm{H}) .{ }^{13} \mathrm{C} \mathrm{NMR}\left(126 \mathrm{MHz}, \mathrm{CDCl}_{3}, \delta\right): 30.2,30.8,122.8\left(\mathrm{q}, J_{\mathrm{CF}}=274 \mathrm{~Hz}\right)$, $123.9\left(\mathrm{q}, J_{\mathrm{CF}}=5 \mathrm{~Hz}\right), 127.2,129.4,130.0,130.3,133.3,136.5,137.0(\mathrm{q}, J=31 \mathrm{~Hz}), 194.8 .{ }^{19} \mathrm{~F} \mathrm{NMR}(470$ $\mathrm{MHz}, \mathrm{CDCl}_{3}, \delta_{\mathrm{F}}$ ): 94.6 (s). IR (neat): 2252, 1684, 1344, 1203, 1132, 903, 721, $650 \mathrm{~cm}^{-1}$. Anal. Calcd for $\mathrm{C}_{12} \mathrm{H}_{11} \mathrm{OF}_{3} \mathrm{~S}: \mathrm{C}, 55.38 ; \mathrm{H}, 4.26$. Found: C, 55.49; H, 4.43.

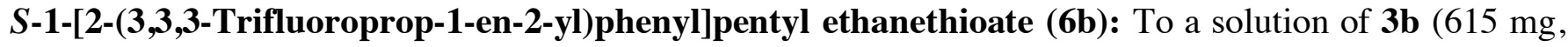
$2.38 \mathrm{mmol})$ and triethylamine $(0.50 \mathrm{~mL}, 3.6 \mathrm{mmol})$ in $\mathrm{CH}_{2} \mathrm{Cl}_{2}(11 \mathrm{ml})$ was added methanesulfonyl chloride $(0.22 \mathrm{~mL}, 2.9 \mathrm{mmol})$ at $0{ }^{\circ} \mathrm{C}$. After the reaction mixture was stirred at $0{ }^{\circ} \mathrm{C}$ for $2 \mathrm{~h}$, saturated 
aqueous $\mathrm{NH}_{4} \mathrm{Cl}$ was added to quench the reaction. The organic layer was washed with brine and dried over $\mathrm{MgSO}_{4}$. Removal of the solvent under reduced pressure gave the residue, crude mesylate $\mathbf{5 b}$, which was used without purification in the following substitution reaction with ethanethioic $S$-acid. To a solution of DBU $(1.04 \mathrm{~mL}, 7.0 \mathrm{mmol})$ in DMF $(3.3 \mathrm{ml})$ was added ethanethioic $S$-acid $(0.50 \mathrm{~mL}, 7.1$ mmol) dropwise at room temperature. The crude mesylate $\mathbf{5 b}$ in DMF $(6.6 \mathrm{ml})$ was added, and the mixture was stirred at room temperature for $20 \mathrm{~h}$. The reaction was quenched with saturated aqueous $\mathrm{NH}_{4} \mathrm{Cl}$. After water was added, organic materials were extracted with AcOEt three times. The combined extracts were washed with brine and dried over $\mathrm{Na}_{2} \mathrm{SO}_{4}$. After removal of the solvent under reduced pressure, the residue was purified by column chromatography (hexane-AcOEt 5:1) to give $\mathbf{6 b}$ (600 mg, $82 \%)$ as a colorless liquid. ${ }^{1} \mathrm{H}$ NMR $\left(500 \mathrm{MHz}, \mathrm{CDCl}_{3}, \delta\right): 0.84(\mathrm{t}, J=7.2 \mathrm{~Hz}, 3 \mathrm{H}), 1.16-1.18(\mathrm{~m}, 1 \mathrm{H})$, $1.26-1.31(\mathrm{~m}, 3 \mathrm{H}), 1.87-1.93(\mathrm{~m}, 2 \mathrm{H}), 2.28(\mathrm{~s}, 3 \mathrm{H}), 4.76(\mathrm{t}, J=7.6 \mathrm{~Hz}, 1 \mathrm{H}), 5.59\left(\mathrm{q}, J_{\mathrm{HF}}=1.1 \mathrm{~Hz}, 1 \mathrm{H}\right)$, $6.19\left(\mathrm{q}, J_{\mathrm{HF}}=1.3 \mathrm{~Hz}, 1 \mathrm{H}\right), 7.22-7.27(\mathrm{~m}, 2 \mathrm{H}), 7.36-7.37(\mathrm{~m}, 2 \mathrm{H}) .{ }^{13} \mathrm{C} \mathrm{NMR}\left(126 \mathrm{MHz}, \mathrm{CDCl}_{3}, \delta\right): 13.8$, $22.4,29.4,30.3,37.1,44.6,122.9\left(\mathrm{q}, J_{\mathrm{CF}}=274 \mathrm{~Hz}\right), 124.1\left(\mathrm{q}, J_{\mathrm{CF}}=5 \mathrm{~Hz}\right), 126.8,127.8,129.3,130.0$, 132.6, $136.6\left(\mathrm{q}, J_{\mathrm{CF}}=31 \mathrm{~Hz}\right), 140.6,194.2 .{ }^{19} \mathrm{~F} \mathrm{NMR}\left(470 \mathrm{MHz}, \mathrm{CDCl}_{3}, \delta_{\mathrm{F}}\right): 95.0$ (s). IR (neat): 2931, $2862,1691,1402,1342,1201,1167,1092,1068,953,629 \mathrm{~cm}^{-1}$. Anal. Calcd for $\mathrm{C}_{16} \mathrm{H}_{19} \mathrm{OF}$ S: C, 60.74; $\mathrm{H}$, 6.05. Found: C, 60.51; H, 6.14 .

4-Trifluoromethyl-3,4-dihydro-1H-2-benzopyran (7a): To a solution of 3a (51 mg, $0.25 \mathrm{mmol})$ in diglyme $(2.5 \mathrm{~mL})$ was added DBU $(42 \mu \mathrm{L}, 0.28 \mathrm{mmol})$. After the reaction mixture was heated at $120{ }^{\circ} \mathrm{C}$ for $48 \mathrm{~h}$, phosphate buffer ( $\mathrm{pH}$ 7) was added to quench the reaction. Organic materials were extracted with $\mathrm{Et}_{2} \mathrm{O}$ three times. The combined extracts were washed with brine and dried over $\mathrm{Na}_{2} \mathrm{SO}_{4}$. After removal of the solvent under reduced pressure, the residue was purified by PTLC (pentane- $\mathrm{Et}_{2} \mathrm{O} 5: 1$ ) to give 7a $(42 \mathrm{mg}, 82 \%)$ as a colorless crystal. ${ }^{1} \mathrm{H} \mathrm{NMR}\left(500 \mathrm{MHz}, \mathrm{CDCl}_{3}, \delta\right): 3.42\left(\mathrm{qm}, J_{\mathrm{HF}}=9.3 \mathrm{~Hz}, 1 \mathrm{H}\right)$, $3.92(\mathrm{dm}, J=12.3 \mathrm{~Hz}, 1 \mathrm{H}), 4.41(\mathrm{dd}, J=12.3,2.3 \mathrm{~Hz}, 1 \mathrm{H}), 4.76(\mathrm{~d}, J=15.2 \mathrm{~Hz}, 1 \mathrm{H}), 4.87(\mathrm{~d}, J=15.2$ $\mathrm{Hz}, 1 \mathrm{H}), 7.07(\mathrm{~d}, J=7.6 \mathrm{~Hz}, 1 \mathrm{H}), 7.26(\mathrm{dd}, J=7.6,7.6 \mathrm{~Hz}, 1 \mathrm{H}), 7.32(\mathrm{dd}, J=7.6,7.6 \mathrm{~Hz}, 1 \mathrm{H}), 7.37$ (d, $J$ $=7.6 \mathrm{~Hz}, 1 \mathrm{H}) .{ }^{13} \mathrm{C} \mathrm{NMR}\left(126 \mathrm{MHz}, \mathrm{CDCl}_{3}, \delta\right): 41.1\left(\mathrm{q}, J_{\mathrm{CF}}=26 \mathrm{~Hz}\right), 63.8\left(\mathrm{q}, J_{\mathrm{CF}}=3 \mathrm{~Hz}\right), 67.7,124.7$, $126.1\left(\mathrm{~d}, J_{\mathrm{CF}}=1 \mathrm{~Hz}\right), 126.2\left(\mathrm{q}, J_{\mathrm{CF}}=281 \mathrm{~Hz}\right), 126.8,128.3,130.2,135.8 .{ }^{19} \mathrm{~F} \mathrm{NMR}\left(470 \mathrm{MHz}, \mathrm{CDCl}_{3}\right.$, $\left.\delta_{\mathrm{F}}\right): 93.7\left(\mathrm{~d}, J_{\mathrm{FH}}=9 \mathrm{~Hz}\right) . \mathrm{IR}$ (neat): 2871, 1734, 1495, 1456, 1350, 1269, 1230, 1153, 1108, 995, 912, 742 $\mathrm{cm}^{-1}$. Anal. Calcd for $\mathrm{C}_{10} \mathrm{H}_{9} \mathrm{OF}_{3}: \mathrm{C}, 59.41 ; \mathrm{H}, 4.49$. Found: C, 59.28; H, 4.54.

1-Butyl-4-trifluoromethyl-3,4-dihydro-1H-2-benzopyran (7b): Compound $7 \mathbf{b}$ was prepared by the method described for 7a. Purification by PTLC (pentane-Et $\left.{ }_{2} \mathrm{O} 10: 1\right)$ gave $7 \mathbf{b}(72 \% ; 87: 13$ diastereomer 
ratio) as a colorless liquid. ${ }^{1} \mathrm{H} \mathrm{NMR}\left(500 \mathrm{MHz}, \mathrm{CDCl}_{3}, \delta\right)$ : (major) 0.90 (t, $\left.J=7.2 \mathrm{~Hz}, 3 \mathrm{H}\right), 1.28-1.46$ (m, 4H), 1.80-1.88 (m, 1H), 1.94-2.01 (m, 1H), $3.26\left(\mathrm{qd}, J_{\mathrm{HF}}=9.2,3.6 \mathrm{~Hz}, 1 \mathrm{H}\right), 3.83(\mathrm{ddq}, J=12.3,3.6,1.8$ $\mathrm{Hz}, 1 \mathrm{H}), 4.47(\mathrm{~d}, J=12.3 \mathrm{~Hz}, 1 \mathrm{H}), 4.74(\mathrm{dd}, J=7.6,2.7 \mathrm{~Hz}, 1 \mathrm{H}), 7.18(\mathrm{~d}, J=7.6 \mathrm{~Hz}, 1 \mathrm{H}), 7.23-7.26(\mathrm{~m}$, 1H), 7.32-7.35 (m, 2H); (minor) $0.94(\mathrm{t}, J=7.2 \mathrm{~Hz}, 3 \mathrm{H}), 1.32-1.55(\mathrm{~m}, 4 \mathrm{H}), 1.70-1.77$ (m, 1H), 1.81$1.89(\mathrm{~m}, 1 \mathrm{H}), 3.38-3.45(\mathrm{~m}, 1 \mathrm{H}), 4.12(\mathrm{~d}, J=4.0 \mathrm{~Hz}, 2 \mathrm{H}), 4.79(\mathrm{dd}, J=10.1,3.2 \mathrm{~Hz}, 1 \mathrm{H}), 7.12(\mathrm{~d}, J=$ $7.6 \mathrm{~Hz}, 1 \mathrm{H}), 7.23-7.26(\mathrm{~m}, 1 \mathrm{H}), 7.31(\mathrm{dd}, J=7.6,7.6 \mathrm{~Hz}, 1 \mathrm{H}), 7.36(J=7.6 \mathrm{~Hz}, 1 \mathrm{H}) .{ }^{13} \mathrm{C}$ NMR $(126$ $\left.\mathrm{MHz}, \mathrm{CDCl}_{3}, \delta\right)$ : (major) 14.0, 22.8, 26.8, 35.4, $41.8\left(\mathrm{q}, J_{\mathrm{CF}}=26 \mathrm{~Hz}\right), 62.8\left(\mathrm{q}, J_{\mathrm{CF}}=3 \mathrm{~Hz}\right), 76.3,124.9$, $126.2\left(\mathrm{q}, J_{\mathrm{CF}}=281 \mathrm{~Hz}\right), 126.4,126.9\left(\mathrm{q}, J_{\mathrm{CF}}=2 \mathrm{~Hz}\right), 128.5,130.5,139.5$; (minor) 14.0, 22.5, 28.1, 34.8, $41.5\left(\mathrm{q}, J_{\mathrm{CF}}=26 \mathrm{~Hz}\right), 58.8\left(\mathrm{q}, J_{\mathrm{CF}}=3 \mathrm{~Hz}\right), 75.0,125.5,126.3\left(\mathrm{q}, J_{\mathrm{CF}}=281 \mathrm{~Hz}\right), 126.4\left(\mathrm{q}, J_{\mathrm{CF}}=2 \mathrm{~Hz}\right)$, 126.6, 128.1, 129.6, 139.8. ${ }^{19} \mathrm{~F}$ NMR $\left(470 \mathrm{MHz}, \mathrm{CDCl}_{3}, \delta_{\mathrm{F}}\right)$ : (major) $93.9\left(\mathrm{~d}, J_{\mathrm{FH}}=9 \mathrm{~Hz}\right)$; (minor) $93.8(\mathrm{~d}$, $J_{\mathrm{FH}}=9 \mathrm{~Hz}$ ). IR (neat) 2956, 2931, 1250, 1155, 1119, 750, $620 \mathrm{~cm}^{-1}$. Anal. Calcd for $\mathrm{C}_{14} \mathrm{H}_{17} \mathrm{OF}_{3}:$ C, 65.10; H, 6.63. Found: C, 65.02; H, 6.77.

1-Phenyl-4-trifluoromethyl-3,4-dihydro-1H-2-benzopyran (7c): Compound 7c was prepared by the method described for 7a. Purification by PTLC (pentane- $\left.\mathrm{Et}_{2} \mathrm{O} 5: 1\right)$ gave $7 \mathbf{b}(86 \% ; 57: 43$ diastereomer ratio) as a colorless crystal.

${ }^{1} \mathrm{H} \mathrm{NMR}\left(500 \mathrm{MHz}, \mathrm{CDCl}_{3}, \delta\right):$ (major) $3.40\left(\mathrm{qd}, J_{\mathrm{HF}}=9.1,3.6 \mathrm{~Hz}, 1 \mathrm{H}\right), 4.07$ (ddq, $J=12.4,3.6,1.8 \mathrm{~Hz}$, 1H), $4.59(\mathrm{~d}, J=12.4 \mathrm{~Hz}, 1 \mathrm{H}), 5.66(\mathrm{~s}, 1 \mathrm{H}), 6.79(\mathrm{~d}, J=7.5 \mathrm{~Hz}, 1 \mathrm{H}), 7.21(\mathrm{dd}, J=7.5,7.5 \mathrm{~Hz}, 1 \mathrm{H}), 7.25$ $(\mathrm{dd}, J=7.5,7.5 \mathrm{~Hz}, 1 \mathrm{H}), 7.34-7.37(\mathrm{~m}, 5 \mathrm{H}), 7.39$ (d, $J=7.5 \mathrm{~Hz}, 1 \mathrm{H})$; (minor) 3.52-3.57 (m, 1H), 4.05$4.12(\mathrm{~m}, 2 \mathrm{H}), 5.88(\mathrm{~s}, 1 \mathrm{H}), 6.93(\mathrm{~d}, J=7.4 \mathrm{~Hz}, 1 \mathrm{H}), 7.19-7.22(\mathrm{~m}, 2 \mathrm{H}), 7.27-7.38(\mathrm{~m}, 5 \mathrm{H}), 7.47(\mathrm{~d}, J=$ $7.4 \mathrm{~Hz}, 1 \mathrm{H}) .{ }^{13} \mathrm{C} \mathrm{NMR}\left(126 \mathrm{MHz}, \mathrm{CDCl}_{3}, \delta\right)$ : (major) $41.5\left(\mathrm{q}, J_{\mathrm{CF}}=26 \mathrm{~Hz}\right), 63.6\left(\mathrm{q}, J_{\mathrm{CF}}=3 \mathrm{~Hz}\right), 80.5$, $126.2\left(\mathrm{q}, J_{\mathrm{CF}}=281 \mathrm{~Hz}\right), 126.4\left(\mathrm{q}, J_{\mathrm{CF}}=2 \mathrm{~Hz}\right), 126.9,127.1,128.4,128.5,128.6,128.9,130.2,138.9$, 141.1; (minor) $41.3\left(\mathrm{q}, J_{\mathrm{CF}}=26 \mathrm{~Hz}\right), 59.4\left(\mathrm{q}, J_{\mathrm{CF}}=3 \mathrm{~Hz}\right), 77.8,126.3\left(\mathrm{q}, J_{\mathrm{CF}}=281 \mathrm{~Hz}\right), 127.2\left(\mathrm{q}, J_{\mathrm{CF}}=2\right.$ $\mathrm{Hz}), 127.2,127.5,127.9,128.3,128.4,129.1,129.6,137.1,140.9 .{ }^{19} \mathrm{~F} \mathrm{NMR}\left(470 \mathrm{MHz}, \mathrm{CDCl}_{3}, \delta_{\mathrm{F}}\right)$ : (major) $93.9\left(\mathrm{~d}, J_{\mathrm{FH}}=9 \mathrm{~Hz}\right.$ ); (minor) 93.8 (d, $\left.J_{\mathrm{FH}}=9 \mathrm{~Hz}\right)$. IR (neat): 3064, 3031, 2870, 1455, 1355, 1243, 1155, 999, 747, $700 \mathrm{~cm}^{-1}$. Anal. Calcd for $\mathrm{C}_{16} \mathrm{H}_{13} \mathrm{OF}_{3}: \mathrm{C}, 69.06 ; \mathrm{H}, 4.71$. Found: $\mathrm{C}, 69.08 ; \mathrm{H}, 4.94$.

4-Difluoromethylene-3,4-dihydro-1H-2-benzopyran (8a): Compound 8a was prepared by the method described for 8c (vide infra). Purification by PTLC (pentane- $\mathrm{Et}_{2} \mathrm{O} 5: 1$ ) gave 8a (38\%) as a colorless liquid. ${ }^{1} \mathrm{H}$ NMR (500 MHz, $\left.\mathrm{CDCl}_{3}, \delta\right): 4.50\left(\mathrm{dd}, J_{\mathrm{HF}}=2.7,2.7 \mathrm{~Hz}, 2 \mathrm{H}\right), 4.79(\mathrm{~s}, 2 \mathrm{H}), 7.05(\mathrm{~d}, J=7.5 \mathrm{~Hz}$, $1 \mathrm{H}), 7.21(\mathrm{dd}, J=7.5,7.5 \mathrm{~Hz}, 1 \mathrm{H}), 7.27(\mathrm{dd}, J=7.5,7.5 \mathrm{~Hz}, 1 \mathrm{H}), 7.61(\mathrm{~d}, J=7.5 \mathrm{~Hz}, 1 \mathrm{H}) .{ }^{13} \mathrm{C}$ NMR $\left(126 \mathrm{MHz}, \mathrm{CDCl}_{3}, \delta\right): 63.2\left(\mathrm{dd}, J_{\mathrm{CF}}=4,4 \mathrm{~Hz}\right), 68.9,85.7\left(\mathrm{dd}, J_{\mathrm{CF}}=20,13 \mathrm{~Hz}\right), 124.7,125.7\left(\mathrm{~d}, J_{\mathrm{CF}}=3\right.$ 
$\mathrm{Hz}), 126.6\left(\mathrm{dd}, J_{\mathrm{CF}}=10,5 \mathrm{~Hz}\right), 127.0\left(\mathrm{dd}, J_{\mathrm{CF}}=2,2 \mathrm{~Hz}\right), 127.3,134.1\left(\mathrm{dd}, J_{\mathrm{CF}}=5,3 \mathrm{~Hz}\right), 152.3\left(\mathrm{dd}, J_{\mathrm{CF}}\right.$ $=296,291 \mathrm{~Hz}) \cdot{ }^{19} \mathrm{~F}$ NMR $\left(470 \mathrm{MHz}, \mathrm{CDCl}_{3}, \delta_{\mathrm{F}}\right): 75.6\left(\mathrm{~d}, J_{\mathrm{FF}}=41 \mathrm{~Hz}, 1 \mathrm{~F}\right), 75.5\left(\mathrm{~d}, J_{\mathrm{FF}}=41 \mathrm{~Hz}, 1 \mathrm{~F}\right) . \mathrm{IR}$ (neat): 2958, 2846, 1722, 1329, 1261, 1236, 1086, 1053, 760, $737 \mathrm{~cm}^{-1}$. Anal. Calcd for $\mathrm{C}_{10} \mathrm{H}_{8} \mathrm{OF}_{2}: \mathrm{C}_{\text {, }}$ 65.93; H, 4.43. Found: C, 66.07; H, 4.59.

4-Difluoromethylene-1-phenyl-3,4-dihydro-1H-2-benzopyran (8c): To a solution of $\mathbf{8 c}$ (53 mg, 0.19 $\mathrm{mmol})$ in $\mathrm{DMF}(2.0 \mathrm{~mL})$ was added $\mathrm{K}_{3} \mathrm{PO}_{4}(81 \mathrm{mg}, 0.38 \mathrm{mmol})$ at room temperature. After the reaction mixture was stirred at $120^{\circ} \mathrm{C}$ for $6 \mathrm{~h}$, phosphate buffer $(\mathrm{pH} 7)$ was added to quench the reaction. Organic materials were extracted with $\mathrm{Et}_{2} \mathrm{O}$ three times. The combined extracts were washed with brine and dried over $\mathrm{Na}_{2} \mathrm{SO}_{4}$. After removal of the solvent under reduced pressure, the residue was purified by PTLC (pentane- $\mathrm{Et}_{2} \mathrm{O}$ 5:1) to give 8c $(21 \mathrm{mg}, 43 \%)$ as a colorless liquid. ${ }^{1} \mathrm{H}$ NMR (500 MHz, $\left.\mathrm{CDCl}_{3}, \delta\right): 4.43$ $\left(\mathrm{ddd}, J=13.2 \mathrm{~Hz}, J_{\mathrm{HF}}=3.6,3.6 \mathrm{~Hz}, 1 \mathrm{H}\right), 4.63\left(\mathrm{dd}, J=13.2 \mathrm{~Hz}, J_{\mathrm{HF}}=2.6 \mathrm{~Hz}, 1 \mathrm{H}\right), 5.76(\mathrm{~s}, 1 \mathrm{H}), 6.81(\mathrm{~d}, J$ $=7.6 \mathrm{~Hz}, 1 \mathrm{H}), 7.13(\mathrm{dd}, J=7.6,7.6 \mathrm{~Hz}, 1 \mathrm{H}), 7.24-7.39(\mathrm{~m}, 6 \mathrm{H}), 7.66(\mathrm{~d}, J=7.6 \mathrm{~Hz}, 1 \mathrm{H}) .{ }^{13} \mathrm{C} \mathrm{NMR}(126$ $\left.\mathrm{MHz}, \mathrm{CDCl}_{3}, \delta\right): 61.0\left(\mathrm{dd}, J_{\mathrm{CF}}=4,4 \mathrm{~Hz}\right), 80.0,86.0\left(\mathrm{dd}, J_{\mathrm{CF}}=24,8 \mathrm{~Hz}\right), 126.4\left(\mathrm{dd}, J_{\mathrm{CF}}=4,2 \mathrm{~Hz}\right), 126.5$ $\left(\mathrm{dd}, J_{\mathrm{CF}}=14,2 \mathrm{~Hz}\right), 126.9\left(\mathrm{dd}, J_{\mathrm{CF}}=2,2 \mathrm{~Hz}\right), 127.1,127.5,128.4,128.5,128.8,136.5\left(\mathrm{dd}, J_{\mathrm{CF}}=6,2 \mathrm{~Hz}\right)$, $140.7,152.2\left(\mathrm{dd}, J_{\mathrm{CF}}=300,287 \mathrm{~Hz}\right) .{ }^{19} \mathrm{~F} \mathrm{NMR}\left(470 \mathrm{MHz}, \mathrm{CDCl}_{3}, \delta_{\mathrm{F}}\right): 75.5\left(\mathrm{~d}, J_{\mathrm{FF}}=41 \mathrm{~Hz}, 1 \mathrm{~F}\right), 75.9(\mathrm{~d}$, $\left.J_{\mathrm{FF}}=41 \mathrm{~Hz}, 1 \mathrm{~F}\right) . \mathrm{IR}$ (neat): 3066, 3032, 2927, 2854, 1732, 1718, 1238, 760, $700 \mathrm{~cm}^{-1}$. Anal. Calcd for $\mathrm{C}_{16} \mathrm{H}_{12} \mathrm{OF}_{2}: \mathrm{C}, 74.41 ; \mathrm{H}, 4.68$. Found: C, 74.42; H, 4.91.

4-Trifluoromethyl-3,4-dihydro-1H-2-benzothiopyran (9a): To a solution of 6a (44 mg, $0.17 \mathrm{mmol})$ in $\mathrm{MeOH}(1.7 \mathrm{~mL})$ was added $\mathrm{K}_{2} \mathrm{CO}_{3}(26 \mathrm{mg}, 0.19 \mathrm{mmol})$ at $0{ }^{\circ} \mathrm{C}$. After the reaction mixture was stirred at $0{ }^{\circ} \mathrm{C}$ for $4 \mathrm{~h}$, phosphate buffer $(\mathrm{pH} 7)$ was added to quench the reaction. Organic materials were extracted with $\mathrm{Et}_{2} \mathrm{O}$ three times. The combined extracts were washed with brine and dried over $\mathrm{MgSO}_{4}$. After removal of the solvent under reduced pressure, the residue was purified by PTLC (pentane- $\mathrm{Et}_{2} \mathrm{O}$ 20:1) to give 7a (34 mg, 92\%) as a colorless liquid. ${ }^{1} \mathrm{H} \mathrm{NMR}\left(500 \mathrm{MHz}, \mathrm{CDCl}_{3}, \delta\right): 3.11(\mathrm{dd}, J=13.6,6.4 \mathrm{~Hz}$, 1H), 3.17 (dd, $J=13.6,5.8 \mathrm{~Hz}, 1 \mathrm{H}), 3.73-3.81(\mathrm{~m}, 1 \mathrm{H}), 3.78$ (s, 2H), 7.17-7.19 (m, 1H), 7.24-7.29 (m, 2H), 7.37-7.38 (m, 1H). ${ }^{13} \mathrm{C} \mathrm{NMR}\left(126 \mathrm{MHz}, \mathrm{CDCl}_{3}, \delta\right): 25.6\left(\mathrm{q}, J_{\mathrm{CF}}=3 \mathrm{~Hz}\right), 30.0,42.9\left(\mathrm{q}, J_{\mathrm{CF}}=26 \mathrm{~Hz}\right)$, $126.4\left(\mathrm{q}, J_{\mathrm{CF}}=282 \mathrm{~Hz}\right), 127.1,127.9,128.6,129.5\left(\mathrm{q}, J_{\mathrm{CF}}=1 \mathrm{~Hz}\right), 130.4\left(\mathrm{q}, J_{\mathrm{CF}}=2 \mathrm{~Hz}\right), 136.1 .{ }^{19} \mathrm{~F} \mathrm{NMR}$ $\left(470 \mathrm{MHz}, \mathrm{CDCl}_{3}, \delta_{\mathrm{F}}\right): 94.6\left(\mathrm{~d}, J_{\mathrm{FH}}=9 \mathrm{~Hz}\right) . \mathrm{IR}$ (neat): 3064, 2921, 1496, 1448, 1340, 1270, 1241, 1151, 1103, 950, 763, $739 \mathrm{~cm}^{-1}$. Anal. Calcd for $\mathrm{C}_{10} \mathrm{H}_{9} \mathrm{~F}_{3} \mathrm{~S}: \mathrm{C}, 55.03 ; \mathrm{H}, 4.16$. Found: $\mathrm{C}, 55.17 ; \mathrm{H}, 4.32$. 
1-Butyl-4-trifluoromethyl-3,4-dihydro-1H-2-benzothiopyran (9b): Compound 9b was prepared by the method described for 9a. Purification by PTLC (pentane- $\left.\mathrm{Et}_{2} \mathrm{O} 30: 1\right)$ gave 9b $(80 \% ; 59: 41$ diastereomer ratio) as a colorless liquid.

${ }^{1} \mathrm{H}$ NMR (500 MHz, $\left.\mathrm{CDCl}_{3}, \delta\right): 0.93(\mathrm{t}, J=7.2 \mathrm{~Hz}, 1.8 \mathrm{H}), 0.94(\mathrm{t}, J=7.2 \mathrm{~Hz}, 1.2 \mathrm{H}), 1.28-1.49$ (m, 3H), 1.55-1.66 (m, 1H), 1.78-2.02 (m, 2H), 3.01 (dd, $J=14.1,4.3 \mathrm{~Hz}, 0.6 \mathrm{H}), 3.05-3.14(\mathrm{~m}, 0.8 \mathrm{H}), 3.20$ (br $\mathrm{dd}, J=14.1,4.3 \mathrm{~Hz}, 0.6 \mathrm{H}), 3.65-3.85(\mathrm{~m}, 2 \mathrm{H}), 7.18-7.31(\mathrm{~m}, 3 \mathrm{H}), 7.34(\mathrm{~d}, J=7.6 \mathrm{~Hz}, 0.6 \mathrm{H}), 7.43(\mathrm{~d}, J$ $=7.6 \mathrm{~Hz}, 0.4 \mathrm{H}) \cdot{ }^{13} \mathrm{C} \mathrm{NMR}\left(126 \mathrm{MHz}, \mathrm{CDCl}_{3}, \delta\right): 14.0,14.0,22.2\left(\mathrm{q}, J_{\mathrm{CF}}=3 \mathrm{~Hz}\right), 22.3\left(\mathrm{q}, J_{\mathrm{CF}}=3 \mathrm{~Hz}\right)$, $22.3,22.4,29.9,30.2,35.0,38.1,41.9,42.1,42.4\left(\mathrm{q}, J_{\mathrm{CF}}=26 \mathrm{~Hz}\right), 43.2\left(\mathrm{q}, J_{\mathrm{CF}}=26 \mathrm{~Hz}\right), 126.3\left(\mathrm{q}, J_{\mathrm{CF}}=\right.$ $282 \mathrm{~Hz}), 126.6\left(\mathrm{q}, J_{\mathrm{CF}}=282 \mathrm{~Hz}\right), 126.6,126.8,127.5,127.9,128.0,128.7\left(\mathrm{q}, J_{\mathrm{CF}}=1 \mathrm{~Hz}\right), 128.8,129.2(\mathrm{q}$, $\left.J_{\mathrm{CF}}=1 \mathrm{~Hz}\right), 129.8\left(\mathrm{q}, J_{\mathrm{CF}}=2 \mathrm{~Hz}\right), 130.6\left(\mathrm{q}, J_{\mathrm{CF}}=2 \mathrm{~Hz}\right), 140.2,140.8 .{ }^{19} \mathrm{~F} \mathrm{NMR}\left(470 \mathrm{MHz}, \mathrm{CDCl}_{3}, \delta_{\mathrm{F}}\right)$ : $95.4\left(\mathrm{~d}, J_{\mathrm{FH}}=9 \mathrm{~Hz}, 1.8 \mathrm{~F}\right) ; 94.6\left(\mathrm{~d}, J_{\mathrm{FH}}=9 \mathrm{~Hz}, 1.2 \mathrm{~F}\right) . \mathrm{IR}$ (neat): 3060, 3025, 2958, 2931, 1493, 1446, 1346, 1273, 1244, 1238, 1151, $1107 \mathrm{~cm}^{-1}$. Anal. Calcd for $\mathrm{C}_{14} \mathrm{H}_{17} \mathrm{~F}_{3} \mathrm{~S}: \mathrm{C}, 61.29 ; \mathrm{H}, 6.25$. Found: C, 61.41; H, 6.43 .

4-Difluoromethylene-3,4-dihydro-1H-2-benzothiopyran (10a): To a solution of $6 \mathbf{6}$ (56 mg, $0.22 \mathrm{mmol}$ ) in THF $(2.2 \mathrm{~mL})$ was added $\mathrm{NaOMe}(24 \mathrm{mg}, 0.43 \mathrm{mmol})$ at $0{ }^{\circ} \mathrm{C}$. The reaction mixture was stirred at $0{ }^{\circ} \mathrm{C}$ for $30 \mathrm{~min}$ and at room temperature for an additional $3 \mathrm{~h}$. Then, phosphate buffer $(\mathrm{pH} 7)$ was added to quench the reaction. Organic materials were extracted with $\mathrm{Et}_{2} \mathrm{O}$ three times. The combined extracts were washed with brine and dried over $\mathrm{Na}_{2} \mathrm{SO}_{4}$. After removal of the solvent under reduced pressure, the residue was purified by PTLC (pentane- $\mathrm{Et}_{2} \mathrm{O} 20: 1$ ) to give $\mathbf{1 0 a}\left(32 \mathrm{mg}, 76 \%\right.$ ) as a colorless liquid. ${ }^{1} \mathrm{H}$ NMR (500 MHz, $\left.\mathrm{CDCl}_{3}, \delta\right): 3.53\left(\mathrm{dd}, J_{\mathrm{HF}}=2.3,2.3 \mathrm{~Hz}, 2 \mathrm{H}\right), 3.79(\mathrm{~s}, 2 \mathrm{H}), 7.16(\mathrm{~d}, J=7.4 \mathrm{~Hz}, 1 \mathrm{H}), 7.21$ $(\mathrm{dd}, J=7.4,7.4 \mathrm{~Hz}, 1 \mathrm{H}), 7.25(\mathrm{dd}, J=7.4,7.4 \mathrm{~Hz}, 1 \mathrm{H}), 7.50(\mathrm{~d}, J=7.4 \mathrm{~Hz}, 1 \mathrm{H}) .{ }^{13} \mathrm{C} \mathrm{NMR}(126 \mathrm{MHz}$, $\left.\mathrm{CDCl}_{3}, \delta\right): 25.1\left(\mathrm{dd}, J_{\mathrm{CF}}=2,2 \mathrm{~Hz}\right), 30.8,87.1\left(\mathrm{dd}, J_{\mathrm{CF}}=23,12 \mathrm{~Hz}\right), 127.0,127.2,127.9,128.5\left(\mathrm{dd}, J_{\mathrm{CF}}=\right.$ $11,1 \mathrm{~Hz}), 129.2\left(\mathrm{dd}, J_{\mathrm{CF}}=5,4 \mathrm{~Hz}\right), 135.2\left(\mathrm{~d}, J_{\mathrm{CF}}=5 \mathrm{~Hz}\right), 152.9\left(\mathrm{dd}, J_{\mathrm{CF}}=297,287 \mathrm{~Hz}\right) .{ }^{19} \mathrm{~F} \mathrm{NMR}(470$ $\left.\mathrm{MHz}, \mathrm{CDCl}_{3}, \delta_{\mathrm{F}}\right): 72.3\left(\mathrm{~d}, J_{\mathrm{FF}}=37 \mathrm{~Hz}, 1 \mathrm{~F}\right), 75.1$ (d, $\left.J_{\mathrm{FF}}=37 \mathrm{~Hz}, 1 \mathrm{~F}\right)$. IR (neat): 3064, 2910, 1712, 1489, 1326, 1228, 1112, 985, 756, $713 \mathrm{~cm}^{-1}$. Anal. Calcd for $\mathrm{C}_{10} \mathrm{H}_{8} \mathrm{~F}_{2} \mathrm{~S}: \mathrm{C}, 60.59 ; \mathrm{H}, 4.07$. Found: C, 60.38; $\mathrm{H}$, 4.15.

1-Butyl-4-difluoromethylene-3,4-dihydro-1H-2-benzothiopyran (10b): Compound 10b was prepared by the method described for 10a. Purification by PTLC (pentane-Et $\mathrm{E}_{2} \mathrm{O} 30: 1$ ) gave 10b (73\%) as a colorless liquid. ${ }^{1} \mathrm{H}$ NMR (500 MHz, $\mathrm{CDCl}_{3}, \delta$ ): 0.91 (t, $\left.J=7.1 \mathrm{~Hz}, 3 \mathrm{H}\right), 1.28-1.41$ (m, 3H), 1.47-1.58 $(\mathrm{m}, 1 \mathrm{H}), 1.77-1.88(\mathrm{~m}, 2 \mathrm{H}), 3.46\left(\mathrm{ddd}, J_{\mathrm{HF}}=14.1,2.4,2.4 \mathrm{~Hz}, 1 \mathrm{H}\right), 3.63\left(\mathrm{ddd}, J_{\mathrm{HF}}=14.1,2.4,2.4 \mathrm{~Hz}\right.$, 
$1 \mathrm{H}), 3.73(\mathrm{t}, J=6.8 \mathrm{~Hz}, 1 \mathrm{H}), 7.15-7.18(\mathrm{~m}, 1 \mathrm{H}), 7.21-7.27(\mathrm{~m}, 2 \mathrm{H}), 7.43-7.47(\mathrm{~m}, 1 \mathrm{H}) .{ }^{13} \mathrm{C}$ NMR $(126$ $\left.\mathrm{MHz}, \mathrm{CDCl}_{3}, \delta\right): 13.9,22.3,22.5,30.1,36.5,43.6,86.9\left(\mathrm{dd}, J_{\mathrm{CF}}=23,13 \mathrm{~Hz}\right), 126.8,127.1,127.3,128.7$, $128.7\left(\mathrm{~d}, J_{\mathrm{CF}}=8 \mathrm{~Hz}\right), 140.5\left(\mathrm{~d}, J_{\mathrm{CF}}=5 \mathrm{~Hz}\right), 152.9\left(\mathrm{dd}, J_{\mathrm{CF}}=296,288 \mathrm{~Hz}\right) .{ }^{19} \mathrm{~F} \mathrm{NMR}\left(470 \mathrm{MHz}, \mathrm{CDCl}_{3}\right.$, $\left.\delta_{\mathrm{F}}\right): 71.3\left(\mathrm{~d}, J_{\mathrm{FF}}=37 \mathrm{~Hz}, 1 \mathrm{~F}\right), 75.0\left(\mathrm{~d}, J_{\mathrm{FF}}=37 \mathrm{~Hz}, 1 \mathrm{~F}\right) . \mathrm{IR}$ (neat): 3066, 2956, 2929, 2858, 1716, 1487, 1254, 1232, 1106, 980, 758 $\mathrm{cm}^{-1}$. Anal. Calcd for $\mathrm{C}_{14} \mathrm{H}_{16} \mathrm{~F}_{2} \mathrm{~S}: \mathrm{C}, 66.11 ; \mathrm{H}, 6.34$. Found: C, 66.10; H, 6.52.

\section{ACKNOWLEDGEMENTS}

We are grateful to Ono Pharmaceutical Co., Ltd. for financial support. We also thank Tosoh F-Tech, Inc. for a generous gift of 2-bromo-3,3,3-trifluoropropene.

\section{REFERENCES AND NOTES}

1. (a) I. Ivanov, S. Nikolova, E. Kochovska, and S. Statkova-Abeghe, ARKIVOC, 2007, 15, 31 and references therein. For reviews, see: (b) E. L. Larghi and T. S. Kaufman, Synthesis, 2006, 187. (c) E. A. Markaryan, A. G. Samodurova, Russ. Chem. Rev., 1989, 58, 479.

2. For a review, see: Y.-C. Xu, Org. Prep. Proced. Int., 1998, 30, 243.

3. For recent examples, see: (a) J. Liu, E. T. Birzin, W. Chan, Y. T. Yang, L.-Y. Pai, C. DaSilva, E. C. Hayes, R. T. Mosley, F. DiNinno, S. P. Rohrer, J. M. Schaeffer, and M. L. Hammond, Bio. Med. Chem. Lett., 2005, 15, 715. (b) C. B. de Koning, J. P. Michael, and W. A. L. van Otterlo, J. Chem. Soc., Perkin Trans. 1, 2000, 799.

4. (a) Y.-C. Xu, Recent Res. Dev. Org. Chem., 2000, 4, 423. (b) M. Yus and F. Foubelo, Adv. Heterocyclic Chem., 2006, 91, 135.

5. For recent examples, see: (a) C. V. Ramana and S. B. Suryawanshi, Tetrahedron Lett., 2008, 49, 445. (b) S. Gowrisankar, H. S. Lee, and J.-N. Kim, Bull. Korean Chem. Soc., 2007, 28, 2501 and references therein. (c) A. Saito, M. Takayama, A. Yamazaki, J. Numaguchi, and Y. Hanzawa, Tetrahedron, 2007, 63, 4039.

6. For the synthesis of fluorinated isochromanes, see: (a) [1-Trifluromethylisochromanes] S. Caron, N. M. Do, J. E. Sieser, P. Arpin, and E. Vazquez, Org. Process Res. Dev., 2007, 11, 1015. (b) [4,4Difluoroisochromanes] S. Arimitsu and G. B. Hammond, J.Org. Chem., 2006, 71, 8665.

7. (a) P. Kirsch, 'Modern Fluoroorganic Chemistry: Synthesis, Reactivity, Applications,' Wiley-VCH, Weinheim, 2004. (b) 'Organofluorine Chemistry, Principles and Commercial Applications,' ed. by R. 
E. Banks, B. E. Smart, and J. C. Tatlow, Plenum Press, New York, 1994. (c) J. T. Welch and S. Eswarakrishnan, 'Fluorine in Bioorganic Chemistry,' John Wily \& Sons, New York, 1991.

8. For reviews on fluorinated heterocycles, see: (a) M. J. Silvester, Adv. Heterocyclic Chem., 1994, 59, 1. (b) M. J. Silvester, Aldrichimica Acta, 1991, 24, 31. (c) R. Plantier-Royon, C. Portella, Carbohydr. Res., 2000, 327, 119.

9. 'Biomedical Frontiers of Fluorine Chemistry,' ed. by I. Ojima, J. R. McCarthy, and J. T. Welch, American Chemical Society, Washington, DC, 1996.

10. (a) V. J. Lee, 'Comprehensive Organic Synthesis,' Vol. 4, ed. by B. M. Trost, Pergamon, Oxford, 1991, p 69. (b) P. Bey, J. R. McCarthy, and I. A. MacDonald, 'Biomedical Frontiers of Fluorine Chemistry,' ed. by J. T. Welch, American Chemical Society, Washington, DC, 1991, Chap. 8.

11. G. Magueur, B. Crousse, M. Ourévitch, D. Bonnet-Delpon, and J.-P. Bégue, J. Fluorine Chem., 2006, $127,637$.

12. R. Nadano, Y. Iwai, T. Mori, and J. Ichikawa, J. Org. Chem., 2006, 71, 8748 and references therein.

13. (a) S. Marcotte, B. Gerard, X. Pannecoucke, C. Feasson, and J.-C. Quirion, Synthesis, 2001, 929 and references therein. (b) J. A. Erickson, and J. I. McLoughlin, J. Org. Chem., 1995, 60, 1626. (c) S. Kaneko, T. Yamazaki, and T. Kitazume, J. Org. Chem., 1993, 58, 2302 and references therein.

14. (a) T. Mori and J. Ichikawa, Chem. Lett., 2004, 33, 1206. (b) T. Mori, Y. Iwai, and J. Ichikawa, Chem. Lett., 2005, 34, 778. See also, Ref. 11.

15. J. Ichikawa, Y. Iwai, R. Nadano, and M. Ikeda, Chem. Asian J., 2008, 3, 393.

16. B. Jiang, Q.-F. Wang, C.-G. Yang, and M. Xu, Tetrahedron Lett., 2001, 42, 4083. 